\title{
THE OCCURRENCE IN MAN OF DOUBLE GANGLIA UPON THE DORSAL ROOTS OF THE SPINAL NERVES
}

\author{
HERBERT N. T. NICHOLS \\ From the Anatomical Laboratory, University of Michigan \\ FIVE FIGURES
}

Nearly all of the more recent standard text books of anatomy that I have examined, as well as the earlier editions of some of these works, speak of the occurrence sometimes in the lumbar and in the sacral regions of dorsal root ganglia that are partially separated into two divisions. Most of these anatomies also mention small accessory ganglia, ganglia aberrantia of Hyrtl, lying upon the dorsal root between the main ganglion and the cord, particularly in the upper cervical region. The literature dealing with the occurrence of double ganglia upon the dorsal roots of the spinal nerves is, however, very meagre. Davida ${ }^{1}$ published an article describing double ganglia in the lumbar and sacral regions. He gives references to no other articless. He examined the lumbar and sacral ganglia from three cadavers. The ganglia from one of the cadavers he describes minutely, the other two not so minutely. In two of the cadavers he found several double ganglia, while in the other he also found a three lobed ganglion. A little later Rattone ${ }^{2}$ published an article describing the occurrence of ganglion cells scattered along the dorsal roots of all the spinal nerves. He refers to the earlier work of Hyrtl, and calls

1Davida: 1880 Ueber die Multiplicität der Lumbal- und Sacral-Spinal-ganglien. Centralblatt für die medicinischen Wissenschaften. Vol. 18, P. 465.

${ }^{2}$ Rattone: 1884 Sur l'existence de cellules ganglionaires dans les racines postórieures des nerfs rachidiens de l'homme. Internationale Monatsschrift für Anatomie und Histologie. vol. 1. 
attention to three treatises upon anatomy ${ }^{3}$ in which aberrant ganglia are mentioned. He speaks of having seen a double lumbar ganglion. "En 1879, sur certaines pièces de système nerveux rachidien, (pièces conservées dans le Museum d'Anatomie normale de l'Université) et que j'ai préparées selon la méthode proposée par Giacomini, Giacomini lui-même me faisait remarquer la duplicité d'un des ganglions lombaires." He also refers to the work of Davida. Rattone states that these are the only articles he found that had any bearing on his investigations.

The occurrence of double ganglia upon the dorsal roots of the spinal nerves was brought to our attention during the course in dissection, and in view of the meagre literature upon the subject, at the suggestion of Professor Streeter, I undertook a more careful study of the ganglia and spinal nerve roots with regard to the details of their gross anatomy. As a result of this study I have been able to establish an unexpected frequency of the doubling of spinal ganglia. It does not occur in the cervical or thoracic region, but in the lumbo-sacral region it is very common. The tendency to division of the ganglion begins at the first lumbar and reaches its maximum at the third, fourth and fifth lumbar, where partial or complete division occurs in from 36 to 44 per cent of the cases. The frequency then quickly diminishes and the phenomenon altogether ceases at the third sacral.

In the anatomical laboratory ${ }^{4}$ at the University of Michigan the routine in dissection is arranged so that a complete study of all of the spinal ganglia is possible. After the dissection of the long muscles of the back and the identification and removal of the shorter ones, the spinous processes and laminae of the vertebrae are removed with chisel and hammer. This lays bare the dura mater of the cord. To expose the portions of the roots and ganglia lying in the intervertebral foramina the articular processes and surrounding bony parts of the vertebrae are cut away with bone pliers. After completely exposing the cervical

${ }^{2}$ W. Krause: 1881 Allgemeine und mikroskopische Anatomie. Hanover 1876 Henle; Handbuch der Nervenlehre des Menschen, 1879; page 505. Schwalbe Lehrbuch der Neurologie, Erlangen; page 802.

4 Streeter: 1909 Laboratory guide in anatomy. 
and brachial plexuses above, parts of the sacrum and of the ilium are removed, having reflected the gluteus maximus muscle, exposing the whole sacral plexus and its branches. Any adipose and connective tissue that still conceals the ganglia and the early course of the nerves is dissected off, thus laying bare the formation and the fisrt part of the course of all the spinal nerves, making a careful study of them possible.

Last year during two of our dissection periods I saved out from the cadavers for more careful examination as many of the roots and ganglia of the spinal nerves as the students had successfully laid bare in dissecting away the surrounding bony parts. The cadavers from which the ganglia were taken were in the main elderly white males. Their average age was fifty-five years. There were two or three females and two or three negroes in the lot. In the removal of the specimens for careful examination all ganglia from the same region and from the same segment of the cord from all of the bodies were placed together. No distinction was made between right and left, and no attempt was made to keep those of one cadaver separate from those of another. The ganglia with their accompanying ventral and dorsal roots I dissected in water under a hand lens. Several ganglia were embedded in paraffin and cross sections prepared for the study of the finer details in the formation of the capsules. Examples in this way were studied of both incomplete and completely divided ganglia.

In the accompanying table 1 , there is shown the number of ganglia examined at each respective level. No attempt was made to include the first cervical ganglia on account of their irregularity and retrogressive tendency. Also on account of their sm zll size I did not study the last sacral and the coccygeal ganglia.

Examination of the table immediately shows that the phenomenon which we are sudying is confined to the lumbar and sacral regions. The occurrence of the tendency to division describes a curve beginning at the level of the first lumbar nerve. The curve then abruptly ascends and reaches its highest point at the third lumbar. Its summit extends from the third to the fifth 
lumbar where it abruptly drops, finally disappearing at the level of the second sacral nerve. In this table there are included under one heading both partially and completely divided ganglia, but as will presently be seen the curves would be similar if complete and incomplete divisions were plotted separately.

TABLE 1

Occurrence of partial or complete division of spinal ganglia

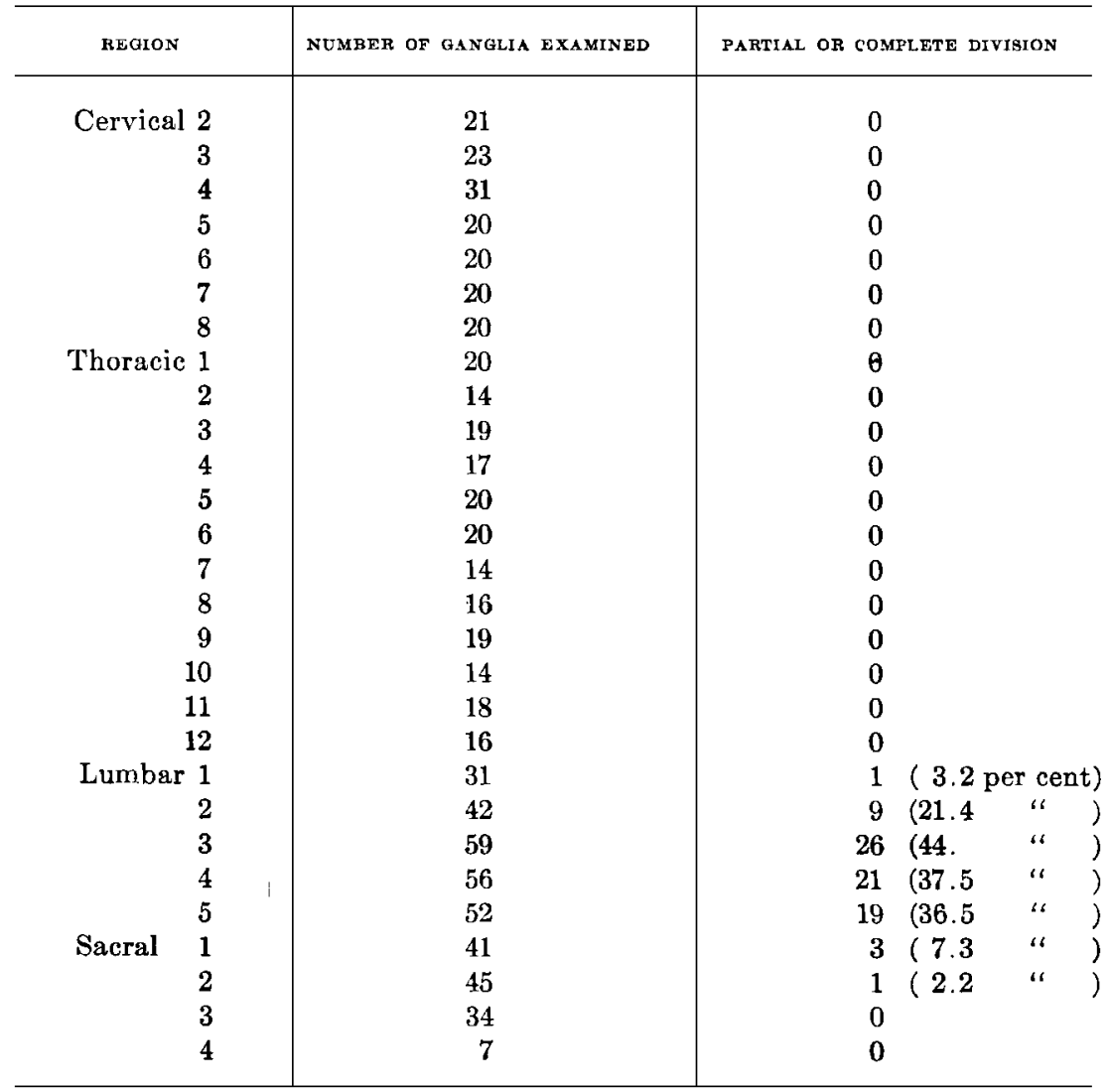




\section{GROSS APPEARANCES}

In the lumbar and sacral regions the ganglia that were single were mainly oval in shape; were flattened dorso-ventrally; had a greater diameter from end to end than from side to side, and varied in shape and size. The upper lumbar were smaller than the lower lumbar and the upper sacral; while the lower sacral were the smallest. The upper lumbar were rounded and more spherical than were the lower lumbar and the upper sacral; while the lower sacral as they decreased in size became more and more fusiform in shape. The fibres of the posterior root left the central end of the ganglion principally in two main bundles. Among these single ganglia there were some that showed, as it were, an unsuccessful attempt to become double by the formation of
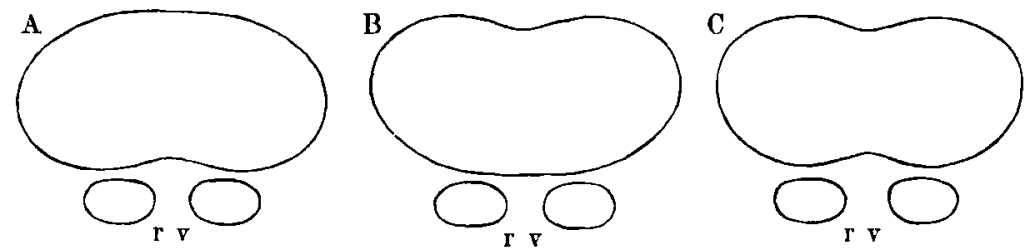

Fig. 1 Diagrammatic cross section through ganglia showing an indentation upon the ventral aspect $(A)$, upon the dorsal aspect $(B)$ and upon both the ventral and the dorsal aspects $(C)$. Note the two divisions of the ventral root $(r v)$ lying upon the ventral aspect of the ganglia.

a shallow longitudinal furrow upon either the ventral aspect or the dorsal aspect or upon both the ventral and dorasl aspects. Fig. 1 shows the outline of a cross section through these varieties of ganglia that have an early aborted cleavage. In several instances there was shown at the end of the ganglion the beginning of a division which was more or less hidden from view by the entering or leaving bundles of nerve fibres. In cases of this sort there was a fissure or notch at the end of the ganglion, as shown in fig. 2, which made a cleft that passed in an anteroposterior plane for a short distance into the ganglion, extending inward for less than one-fourth of its length.

The accompanying table 2 gives a condensed statement of the degrees and varieties of incomplete division that were met with 


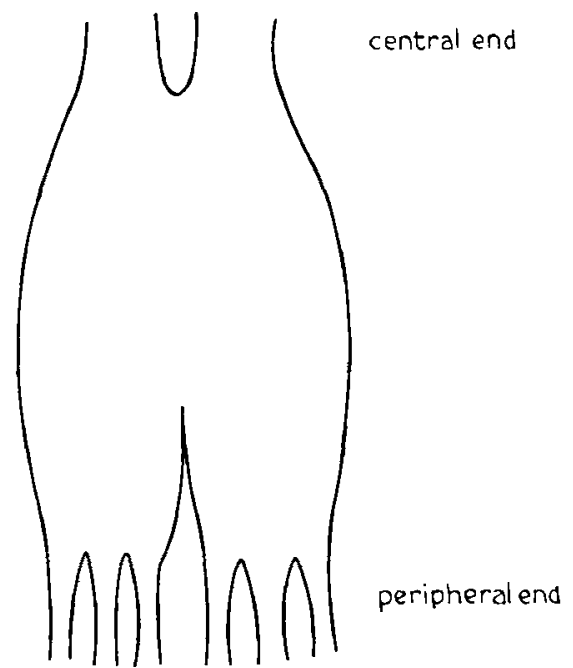

$\mathbf{A}$

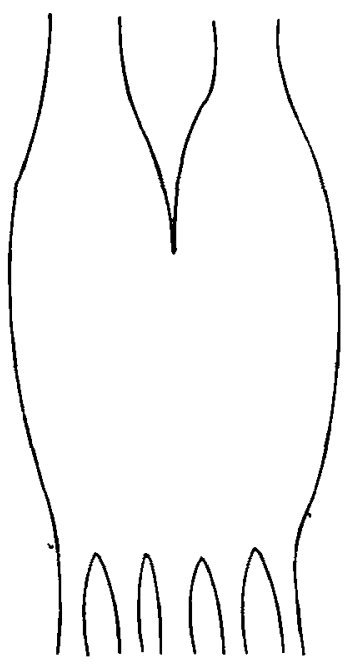

B

Fig. 2 Diagrammatic longitudinal section through ganglia showing complete cleavage for one-third their length, $(A)$ at the central end and $(B)$ at the peripheral end. Note the numerous bundles of entering fibres at the peripheral end and the two bundles of emergent fibres at the central end.

which were as will be seen diverse and varied. They are classed into several groups according to their characteristics as is briefly summed up in the different divisions and subdivisions of the table. It will be noticed that the different stages of division or duplicity very readily fall into a series of an ascending, ever increasing degree of cleavage. Ganglia that are classed as single, with the modification that they show a beginning division, start the series, which passes up through the different gradations of cleavage till it reaches the stage where the ganglionic tissue is all but completely separated into two distinct parts.

In many instances border-line ganglia were found which could be classed either under single ganglia showing a tendency to division or under double ganglia in which the division was incomplete.

In some of the ganglia of this class, (table 2, 2) the ganglion instead of being of a regular oval shape, was, in the main, oval, 
but had, at the peripheral end on one or on both aspects, a bulging enlargement which was separated from the rest of the ganglion, not by a fissure, but by only a shallow groove or aborted division cleft. This bulging or protuberance, as we may call it, had a greater dorso-ventral diameter than did the rest of the ganglion. Furthermore, the bulging protuberance did not extend clear across the entire breadth of the ganglion, but occupied only one-third to two-thirds of its breadth. Also the protuberance, in some of the cases, extended considerably farther toward the periphery than did the rest of the ganglion.

A few of the ganglia (table 2, 3 ) showed sufficient indications of divisions at both ends and on the ventral aspect, or at both ends and upon both ventral and dorsal aspects to entitle them to classification among the ganglia that showed an incomplete separation of ganglionic tissue. They could no longer be regarded as single ganglia. Such ganglia before their dissection had a marked appearance of duplicity. In one ganglion of this sort
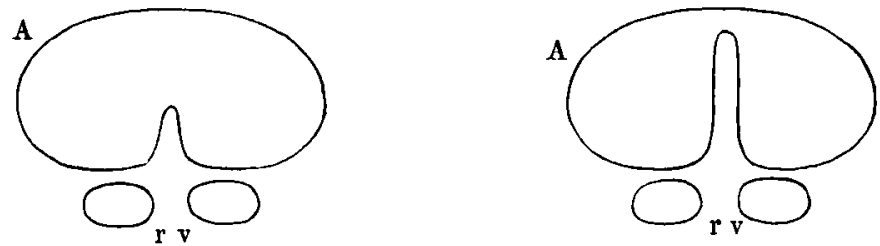

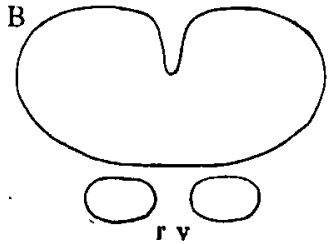

3

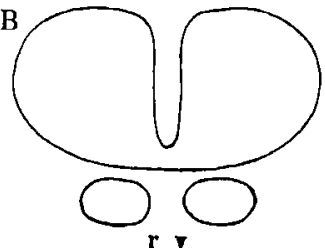

4

Fig. 3 Diagrammatic cross section of ganglia showing a partial cleavage, $(A)$ upon the ventral aspect, and $(B)$ upon the dorsal aspect. The two divisions of the ventral root $(r v)$ show upon the ventral aspect.

Fig. 4 Diagrammatic cross section of ganglia showing a cleavage extending nearly through the ganglionic tissue, $(A)$ from the ventral aspect, and $(B)$ from the dorsal aspect. The two divisions of the ventral root $(r v)$ show upon the ventral aspect. 


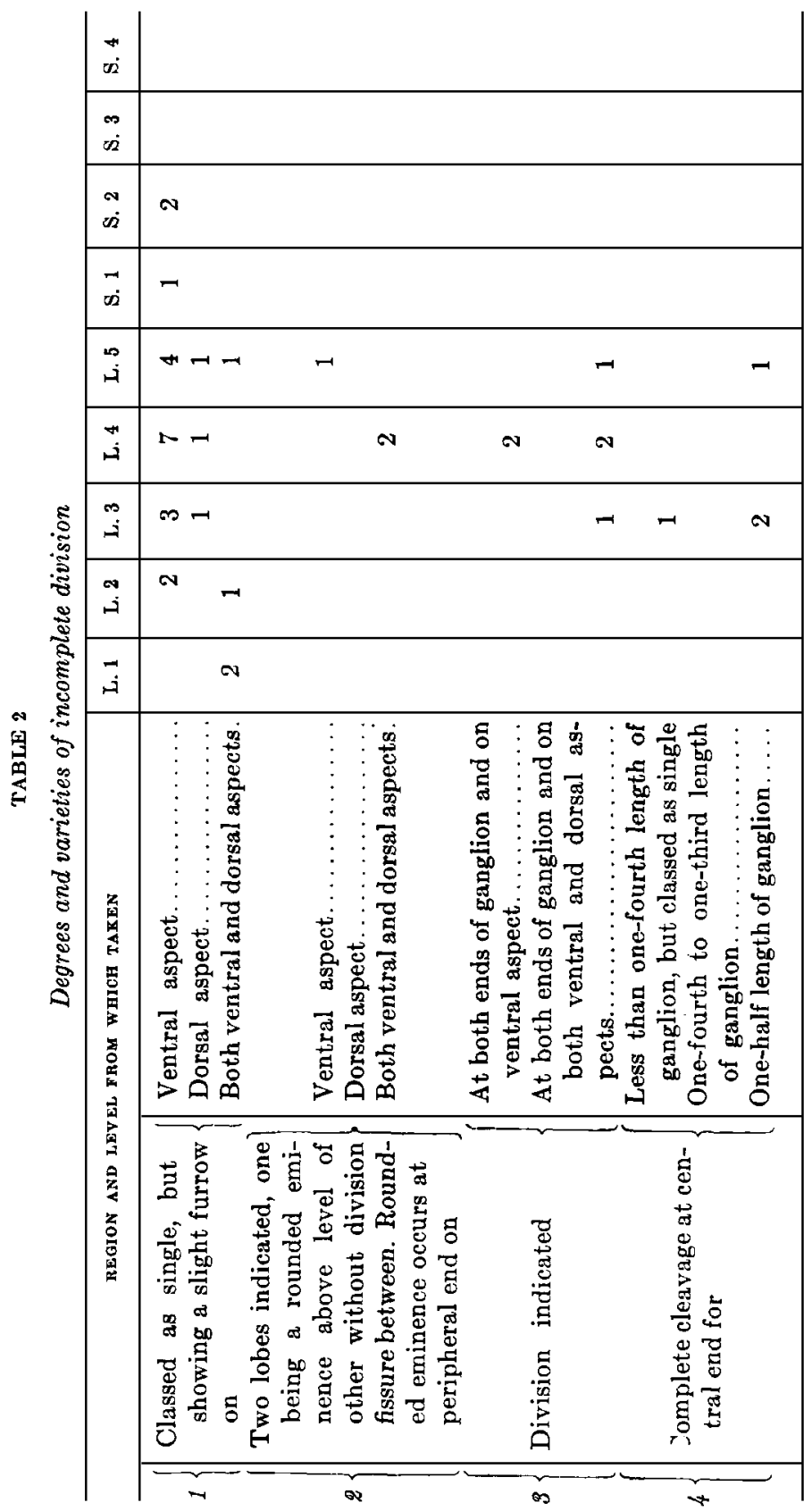




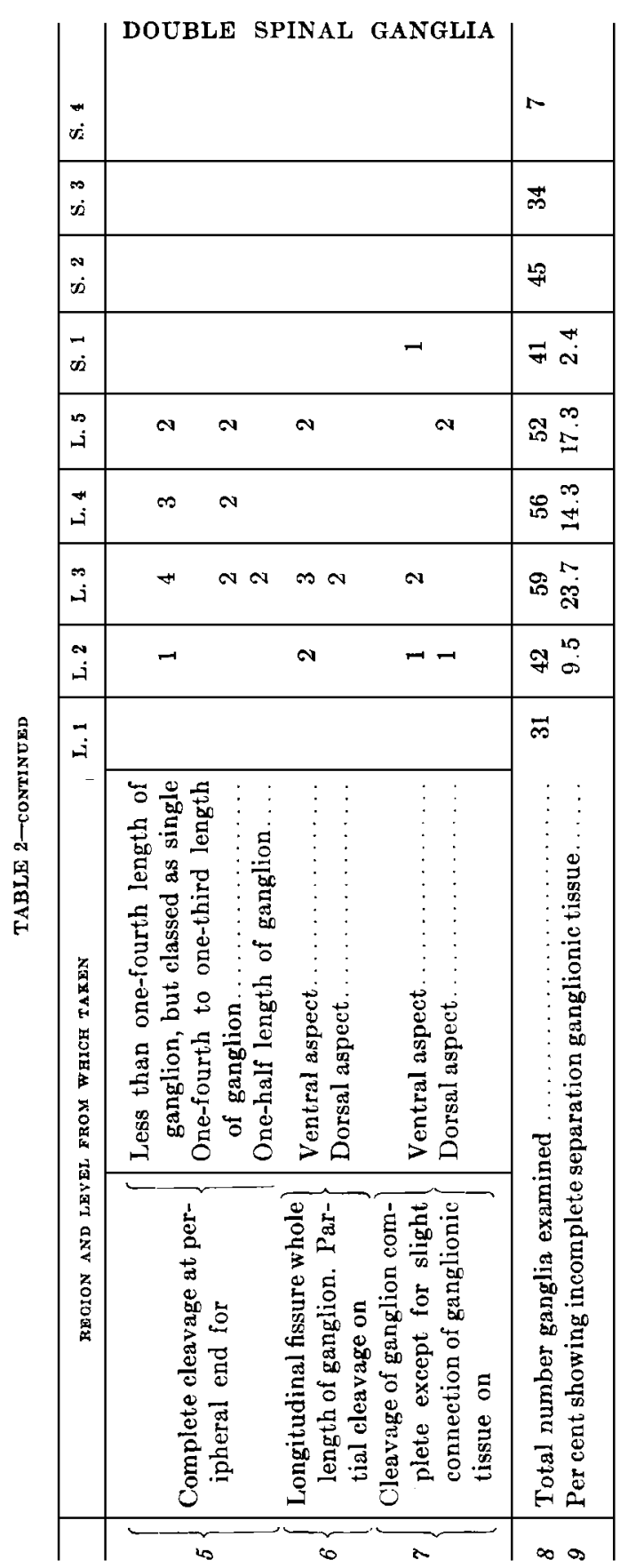


there seemed to be three lobes. About one-fourth of the ganglionic mass was partially constricted off at both ends and on both aspects. The remaining three-fourths of the ganglionic mass really constituted one lobe, although there was a broad cleft extending up into it for one-third of its length from the peripheral end.

The percentages of the different degrees of cleavage of the ganglia are given in the accompanying table 3.

In figs. 2, 3 and 4 are shown some of the ordinary types of incompletely divided ganglia. These are classified in table 2 under types $4,5,6$ and 7 . As a rule where there was a tendency to septum formation, dividing the ganglion longitudinally, (figs. 3 and 4) this occurred on the ventral aspect of the ganglion. There were 40 instances in which there was some degree of ventral invagination of this character and 16 cases of invagination of the dorsal aspect. In 8 of the cases cited the invagination or septum formation occurred on both the ventral and dorsal aspects at the same time in the same ganglion, so that these 8 are included in both the 40 and 16 cases mentioned above. This leaves then 32 instances of septum formation from the ventral alone to compare with 8 instances from the dorsal alone, or a ratio of 4 to 1 .

In the cases where there was a partial splitting of the ganglion at either end, as shown in fig. 2 , it occurred more frequently at the peripheral end. Of all the ganglia examined there were 42 that showed a division at the peripheral end and 17 that were divided at the central end. If we deduct the ganglia that are counted in this twice, there are left 29 cases of division at the peripheral end and 4 cases of division at the central end or about 7 to 1 , which shows that the division at the central end is relatively infrequent.

The ganglia in which there was a complete division of ganglionic tissue are listed in the accompanying table 4 . It will be seen that in a few instances the separation of the ganglionic tissue was complete except for a slight fibrous connection at the proximal end. Here there was a decussation of a few nerve fibres caused by the passage of centripetal sensory axones from one division of the ganglion into the opposite dorsal root fasciculus. 

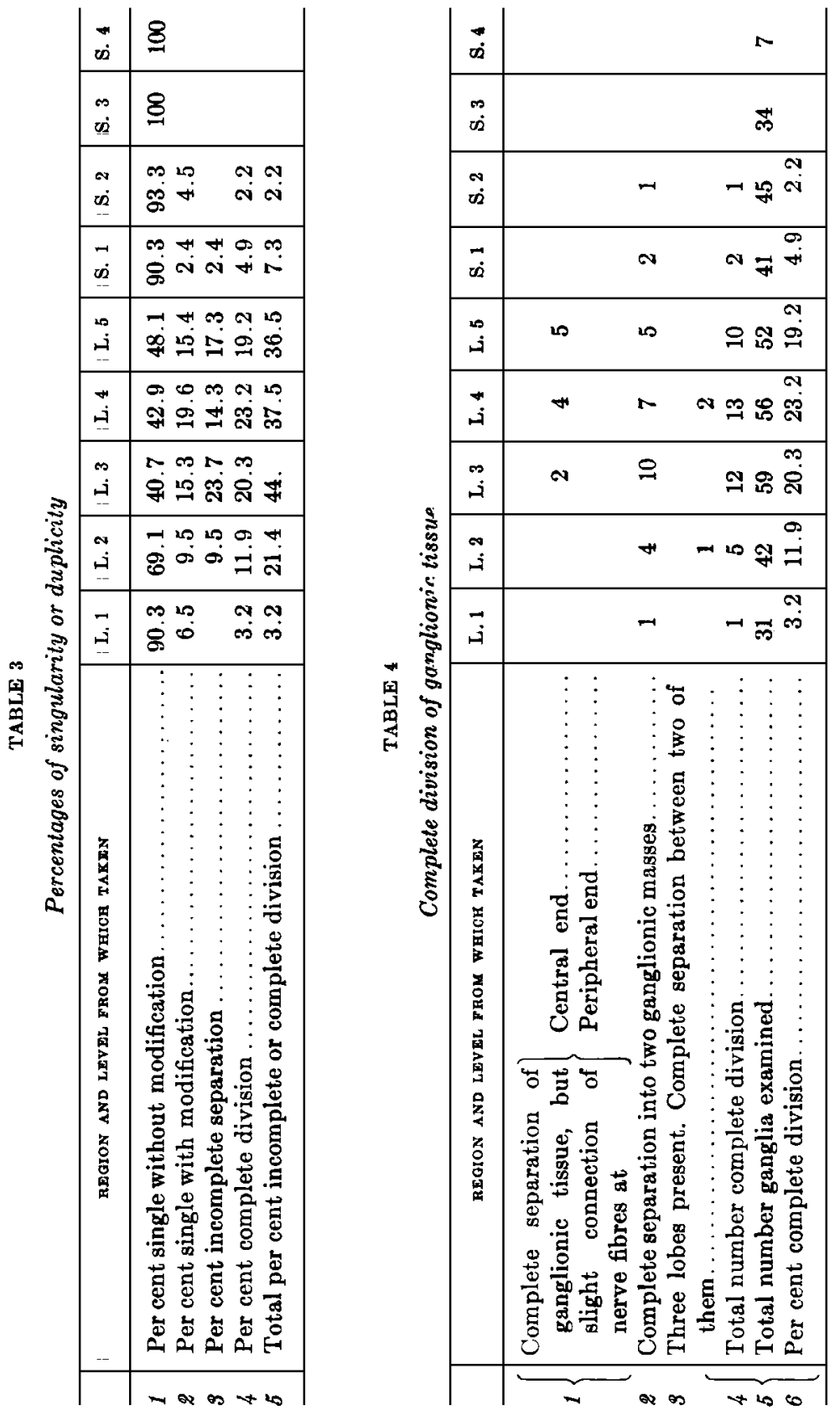
Three of the ganglia examined had three lobes each. In two of these instances the three lobes were entirely separated from each other. In the other case, two of the three lobes were united by a thin bridge of protoplasmic tissue. The one of these three lobed ganglia from the second lumbar level had a relatively very small oval little mass of ganglionic tissue lying squarely upon and impressing the dorsal aspect of its main mass. One small afferent bundle of nerve fibres entered the peripheral end of the little mass while one small efferent bundle of nerve fibres came away from its central end. The main mass of the ganglion was broader than long. It had upon its dorsal aspect an impression made by the little ganglion lying upon it. Both ends, central and peripheral, contained a deep, broad notch indicative of division. Along the whole length of the ventral aspect a broad, deep furrow extended from notch to notch. Several small afferent bundles of nerve fibres entered at the peripheral end; while at the central end the efferent fibres came away in a number of independent fasciculi grouped into two main bundles, one from either division of the main mass. The ventral root, in this case, as it passed over the central aspect of the ganglion divided into only two divisions. All three lobes of this ganglion lay with their central ends equally distant from the cord.

One of the two trip!e ganglia from the fourth lumbar level did not have each of its three lobes entirely separated from the other two. The smallest of the three lobes, however, was entirely separated from the other two. This small lobe was elongated, fusiform in shape, and lay along the side of the other two. It had a single afferent bundle of nerve fibres entering its peripheral end, and a single efferent bundle coming away from its central end. The other two lobes of this ganglion had upon their dorsal aspect a bridge of ganglionic tissue connecting them together, the dorsal aspect of the central end of one to the dorsal aspect of the other along its middle. Upon their ventral aspect there was a deep groove, cleft or fissure extending nearly through to the dorsal aspect where it was interrupted by the bridge of ganglionic tissue. Several afferent nerve fibre bundles entered each 
of the two connected lobes at their peripheral end. The efferent fibres came away from the central end in two main bundles, one from each of the two united lobes. The triple condition of the ganglion under consideration showed very much better from the ventral aspect than from the dorsal. All three of the lobes had their central ends at slightly different distances from the cord. The motor root divided into three divisions as it passed over the ventral aspect of the ganglion, one of the divisions passing to each of the three groups of afferent nerve fibre bundles.

The other of the two triple ganglia from the fourth lumbar level had each of its three lobes completely separated from the other two. Two of the lobes were of about the same size and shape, both being oval. The third lobe was larger in circumference and longer than either of the other two. Several small afferent bundles entered each of the three lobes at their peripheral end. There were three efferent bundles leaving the ganglion, one from the central end of each of the three lobes. All three of the lobes had their central ends at slightly different distances from the cord. The motor root divided into three divisions corresponding to the three lobes of the ganglion.

The relative position of the two lobes where the ganglion is partly or completely divided is shown in table 5 . It will be seen that where there is a complete separation of ganglionic tissue the two divisions of the ganglion are frequently unequally distant from the spinal cord, and in a few instances one of the divisions was found lying entirely beyond the peripheral end of the other. Where there was an incomplete separation of the ganglionic tissue the two divisions were situated in the majority of the cases equally distant from the cord. In both partially and completely divided ganglia the two divisions were of unequal size more often than not. Combining the complete and incomplete separation there were 47 ganglia in which the divisions were of unequal size, as against 30 in which they were of equal size. 
HERBERT N. T. NICHOLS

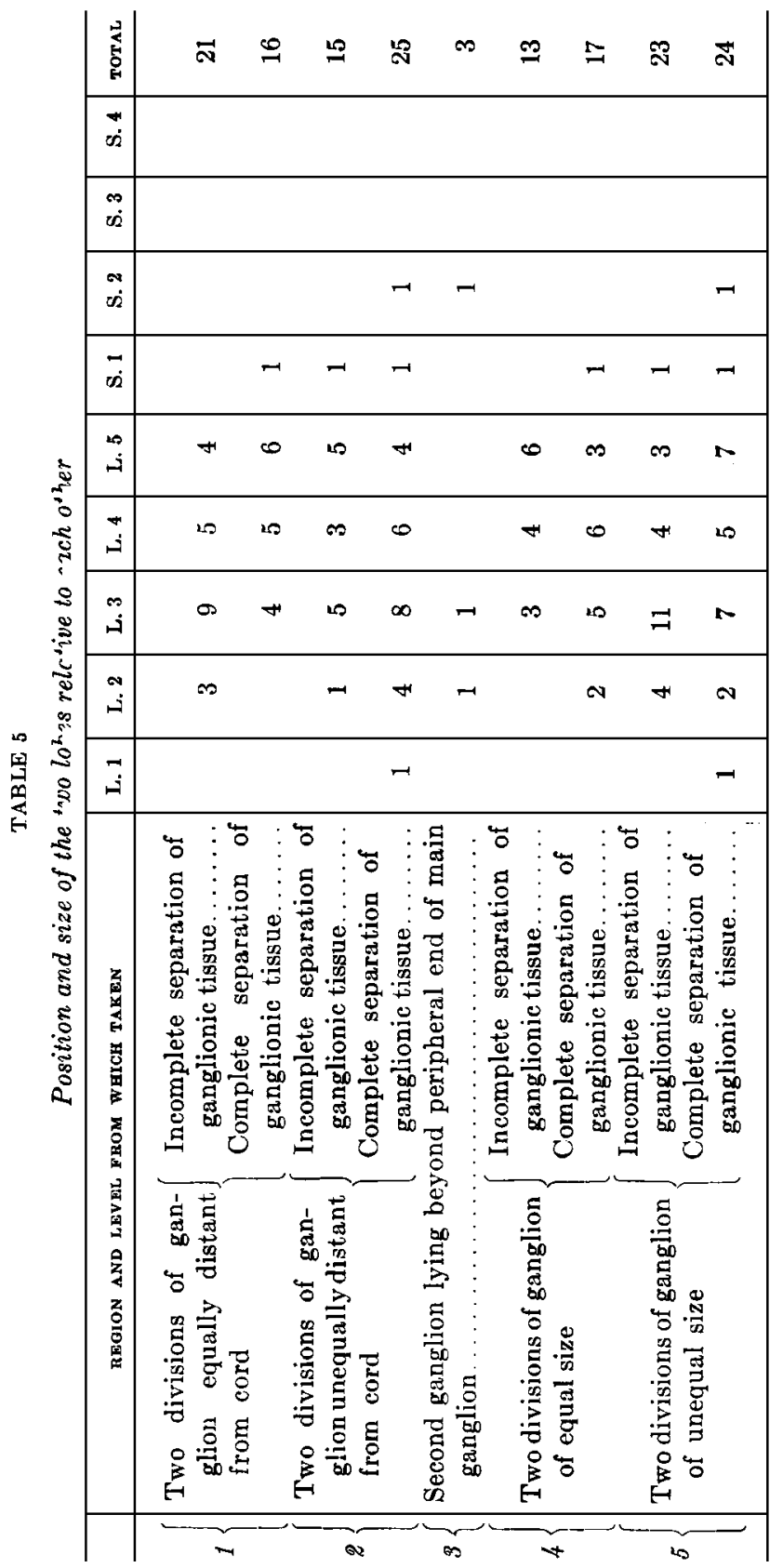




\section{MICROSCOPICAL EXAMINATION}

The accompanying figure (fig. 5) is from a cross section through a typical double ganglion. In preparing this ganglion for a cross section only enough of the surrounding adipose and loose fibrous connective tissue was picked away to prevent a too ragged appearance of the periphery of the preparation. The epineurium of the ventral root and the capsule of the ganglion were left undisturbed. A transverse block of tissue was cut from the central part of the ganglion and its accompanying ventral root. In the figure we see the ganglionic mass completely separated into two divisions of unequal size. One of them, the smaller, is nearly round. The other, the larger, is of an oblong shape. Each has its own fibrous connective tissue capsule. A small space intervenes between the capsules of the two divisions, which is occupied by loose, fibrous connective tissue, a little adipose tissue, and, small vessels. Several small bundles of nerve fibres may be seen in each division. A process of fibrous tissue, extending inward from the capsule of the larger division on one side toward an indentation in the ganglionic tissue and a thickening in the capsule upon the other side, forms a partial or incomplete septum within this portion of the ganglion. The irregular cleft that is seen passing along the line of continuation of this septum is an artefact. Upon the side of the section corresponding to the ventral aspect of the ganglion are two bundles of nerve fibres, the ventral root fibres, cut in cross section. Each bundle has its own epineurium. They are oval in shape lying end to end, and are placed partially opposite the sarrow space intervening between the two divisions of the ganglion. A considerable amount of adipose tissue, loose connective tissue and vessels lies between these two divisions of the ventral root and the corresponding division of the ganglion.

The capsule of the ganglion in the cases where the ganglionic tissue was completely separated into two parts, was in some instances completely divided as is shown in fig. 5. In other cases the capsule was divided upon one aspect of the ganglion only. Upon the other aspect of the ganglion where the division 


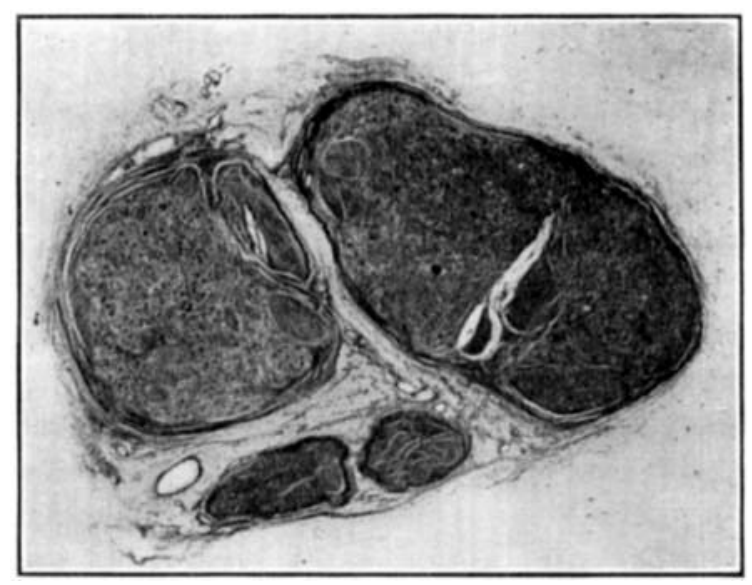

Fig. 5 Cross section of a double third lumbar ganglion, showing complete division into two parts. Note the capsule of either division of the ganglion; the space between the two divisions; the two divisions of the ventral root with their epineurium; the surrounding adipose and loose fibrous connective tissue with blood vessels interspersed; the ganglion cells which appear as black specks a little smaller than pin heads, and the fasciculi of nerve fibres within the two divisions of the ganglion. From a photograph of a $10 \mu$ section stained in hematoxylin and eosin. $\times 90$.

did not occur there was a triangular shaped cleft in the ganglionic tissue which was occupied by a thickening in the capsule from which a process of connective tissue passed inward becoming a septum. This connective tissue septum at a variable distance from its origin split into two processes which diverging as they proceeded onward became continuous with the two arms of the divided capsule entering from the opposite side. The plane of cleavage was in all instances dorso-ventral.

Where the ganglion was not completely separated into two divisions, in some instances there was an invagination of the capsule upon one aspect of the ganglion for a variable distance. In other instances the capsule was continuous across the cleft between the two divisions, passing directly over the plane of cleavage at right angles to it from one lobe of the ganglion to the other. The septum here was a process of connective tissue of varying breadth that passed inward from the capsule toward, 
but not to, the opposite aspect of the ganglion. In cases like the one just mentioned of an incomplete septum as well as in the ones where the capsule extended nearly or clear through to the opposite aspect, there occurred along the central region of the septum or of the prolongation of the invaginated capsule a zone of fibrous connective tissue of less density than that upon either side of it, indicating a distinct line of cleavage between the two divisions of the ganglion. On the aspect of the ganglion where the septum would have emerged, if it had been complete, there was a slight indentation in the ganglionic tissue with a corresponding thickening in the connective tissue of the capsule at that point, suggestive of an aborted attempt to give off an inward passing septum, or to form an invagination of the capsule. In cases where the septum or continuation of the invaginating capsule failed to pass clear through, there was noticeable an arrangement of the connective tissue of the ganglion so as to lie in line with the direction of the septum indicating where the cleavage would have occurred had the septum been complete.

It was found that the invagination of the capsule and the inward passage of the septum, where neither resulted in a complete cleavage, started from the ventral aspect much oftener than from the dorsal. I also found that the degree of cleavage had no influence upon the relative size of the lobes; that in point of relative size the tendency was toward an unequal division; and that in many instances, especially so in the complete divisions, the central ends of the two lobes of the double ganglia did not lie in a single plane placed at right angles to the long axis of the ganglion.

In connection with the study of the ganglia the following features were noted regarding the nerve roots belonging to them. In some of the ganglia, particularly in the lumbar and in the upper sacral regions, the motor root at a point central to the central end of the ganglion on the dorsal root divided into two bundles as it passed over the ventral aspect of the aforesaid dorsal root ganglion. The division was a constant occurrence in all cases where the ganglion was relatively broad from side to side; where it was double, or where it showed indications of duplicity. The two divisions of the ventral root, lying side by sideat first, diverged 
slightly as they approached and passed beyond the peripheral end of the ganglion to join with the dorsal root fibres in the formation of the two primary divisions of the spinal nerves.

As a characteristic of the ventral root, whether occurring as a single nerve bundle, or being divided into two bundles, it very frequently was of an oval cross sectional outline, regardless of whether it was bound down tightly to the ganglion, was placed just within the capsule of the ganglion, or was some slight distance away. As an exception to this oval characteristic the small motor root of the thoracic region showed a greater tendency to roundness than was seen in any of the other regions of the cord. The same oval cross sectional shape or outline held true with even greater constancy for the two divisions of the ventral root where the motor fibres were grouped in two bundles than was the case where this root was undivided.

At the peripheral end of all the larger and of many of the smaller dorsal root ganglia the entering sensory nerve fibres were grouped into a number of bundles of irregular size. In the regions of the cord where the roots and the ganglia are the largest the fibres entering the ganglia from the periphery were arranged in the greatest number of bundles. The division or partial division of the ganglia did not affect this grouping of the entering fibres in the least; for in case the ganglion was double each division then took its proportionate share of the entering bundles.

\section{RESUME}

The ventral root, usually oval itself, was frequently divided into two oval bundles in the vicinity of the ganglion. The dorsal root fibres, central to the ganglion, were grouped into one, two or several bundles; while peripherally to the ganglion they were grouped into a number of small bundles. Where division of the ganglion occurred, it was the result of either an invagination of the capsule, or of a septum passing in from the capsule. The degree of division ranged from the ganglion that was single to the one that was triple with three completely separated lobes. Division occurred much oftener at the peripheral end than at the central end. 
Among the cervical and the thoracic ganglia that were examined there were none that were double. In the lumbar region and in the upper sacral region there was a marked tendency to occur double, either from an incomplete or from a complete separation of the ganglionic tissue into two divisions. This tendency toward division, whether complete or incomplete, was most marked in the third, the fourth and the fifth lumbar levels occurring here as often as once in every third case; whereas complete division of the ganglia in the same levels occurred once in every fifth case.

In conclusion I wish to acknowledge my indebtedness to Prof. Novy for the preparation of the photograph which is reproduced in fig. 5, and I wish also to take this opportunity to thank Professor Streeter, without whose advice and stimulus this study would not have been completed. 